\title{
Novel formulation, cytotoxicity, antioxidant, and anti- human lung cancer properties of gold nanoparticles containing Verbascum thapsus $L$. leaf aqueous extract
}

\section{Type}

Research paper

\section{Keywords}

Gold nanoparticles, Verbascum thapsus L, lung well-differentiated bronchogenic adenocarcinoma, lung moderately differentiated adenocarcinoma, lung poorly differentiated adenocarcinoma

\begin{abstract}
Introduction

In the present study, gold nanoparticles were prepared and synthesized in aqueous medium using V. thapsus leaf extract. We assessed the anti-human lung cancers potentials of these nanoparticles against well-differentiated bronchogenic adenocarcinoma, moderately differentiated adenocarcinoma of the lung, and poorly differentiated adenocarcinoma of the lung cell lines.
\end{abstract}

\section{Material and methods}

AuNPs were characterized and analyzed by common nanotechnology techniques including FT-IR and UV-Vis. Spectroscopy, Field Emission-Scanning Electron Microscopy, and Transmission Electron Microscopy. For determining of anti-human lung cancer properties of $\mathrm{HAuCl}$, V. thapsus, and AuNPs, MTT assay was used on normal (HUVECs), well-differentiated bronchogenic adenocarcinoma (HLC-1), moderately differentiated adenocarcinoma of the lung (LC-2/ad), and poorly differentiated adenocarcinoma of the lung (PC-14) cell lines.

\section{Results}

In the FT-IR test, the presence of many antioxidant compounds with related bonds caused the excellent condition for reducing of gold in the gold nanoparticles. In UV-Vis, the clear peak in the wavelength of $548 \mathrm{~nm}$ indicated the formation of gold nanoparticles. AuNPs had excellent antihuman lung cancer effects dose-dependently against HLC-1, LC-2/ad, and PC-14 cell lines. The best result of anti-human lung cancer activities of AuNPs against above cell lines was observed in the case of the PC-14 cell line.

\section{Conclusions}

In conclusion, the synthesized AuNPs showed significant anti-human lung cancer properties against well-differentiated bronchogenic adenocarcinoma, moderately differentiated adenocarcinoma of the lung, and poorly differentiated adenocarcinoma of the lung cell lines in a dose depended on manner. 
Novel formulation, cytotoxicity, antioxidant, and anti-human lung cancer properties of gold nanoparticles containing Verbascum thapsus L. leaf aqueous extract

Kaijin $\mathrm{Lu}^{1} \#$, Yan $\mathrm{Ou}^{2} \#$, Lihao Jiang ${ }^{3}$, Yijia Xiao ${ }^{4 *}$, Arunachalam Chinnathambi ${ }^{5}$, Tahani Awad Alahmadi ${ }^{6}$, Milton Wainwright ${ }^{7}$

${ }^{1}$ Department of Thoracic Surgery, Taizhou People's Hospital of Jiangsu Province, Taizhou city, Jiangsu Province, 225300, China

${ }^{2}$ Respiratory Medicine, Chongqing Armed Police Corps Hospital, Chongqing, 400020, China

${ }^{3}$ Department of Oncology, The People's Hospital of Dazu, Chongqing, 402360, China

${ }^{4}$ Department of Respiratory and Critical Care Medicine, Changsha Central Hospital of Hunan Province, Changsha, Hunan, 410000, China

${ }^{5}$ Department of Botany and Microbiology, College of Science, King Saud University, PO Box -2455, Riyadh 11451, Saudi Arabia.

${ }^{6}$ Department of Pediatrics, College of Medicine and King Khalid University Hospital, King Saud University, Medical City, PO Box-2925, Riyadh -11461, Saudi Arabia.

${ }^{7}$ Department of Molecular Biology and Biotechnology, University of Sheffield, Sheffield S10 2TN, UK.

Note:\# Means Kaijin Lu and Yan Ou contributed equally to the article.

*Corresponding author: Yijia Xiao: xiaoyijia121@sina.com 


\section{ABSTRACT}

In the present study, gold nanoparticles were prepared and synthesized in aqueous medium using $V$. thapsus leaf extract. We assessed the anti-human lung cancers potentials of these nanoparticles against well-differentiated bronchogenic adenocarcinoma, moderately differentiated adenocarcinoma of the lung, and poorly differentiated adenocarcinoma of the lung cell lines. AuNPs were characterized and analyzed by common nanotechnology techniques including FT-IR and UV-Vis. Spectroscopy, Field Emission-Scanning Electron Microscopy, and Transmission Electron Microscopy. In the FT-IR test, the presence of many antioxidant compounds with related bonds caused the excellent condition for reducing of gold in the gold nanoparticles. In UV-Vis, the clear peak in the wavelength of $548 \mathrm{~nm}$ indicated the formation of gold nanoparticles. For determining of anti-human lung cancer properties of $\mathrm{HAuCl}_{4}, V$. thapsus, and AuNPs, MTT assay was used on normal (HUVECs), welldifferentiated bronchogenic adenocarcinoma (HLC-1), moderately differentiated adenocarcinoma of the lung (LC-2/ad), and poorly differentiated adenocarcinoma of the lung (PC-14) cell lines. AuNPs had excellent antihuman lung cancer effects dose-dependently against HLC-1, LC-2/ad, and PC-14 cell lines. The best result of anti-human lung cancer activities of AuNPs against above cell lines was observed in the case of the PC-14 cell line. In conclusion, the synthesized AuNPs showed significant anti-human lung cancer properties against welldifferentiated bronchogenic adenocarcinoma, moderately differentiated adenocarcinoma of the lung, and poorly differentiated adenocarcinoma of the lung cell lines in a dose depended on manner.

KEYWORDS Gold nanoparticles; Verbascum thapsus L.; lung well-differentiated bronchogenic adenocarcinoma; lung moderately differentiated adenocarcinoma; lung poorly differentiated adenocarcinoma. 


\section{INTRODUCTION}

Cancer is a genetic disease that includes 277 types of diseases. There are also more than 100,000 types of chemicals in our environment, of which only 35,000 have been analyzed and about 300 of them produce cancer. The remaining 65,000 chemicals in nature have not yet been tested. Cancer occurs due to uncontrolled cell division, which is the result of environmental factors and genetic disorders. ${ }^{[1-3]}$ The four key genes involved in cancer cell conduction include DNA repair genes, tumor suppressor genes, oncogenes, and programmed death genes. ${ }^{[2,3]}$ If a genetic mutation is produced in a cell, normal cells go out of their way and are affected by new commands that progress to cancer cells. In addition to chemicals, sunlight, shortwave, viruses and bacteria also have a special role in causing cancer. ${ }^{[4,5]}$ Cancers have existed since the beginning of mankind. In recent decades, advances in computer molecular medicine have been able to not only study the causes and mechanisms of this deadly disease but also to perform better in its early diagnosis and treatment. ${ }^{[5-7]}$ More than $50 \%$ of cancers are currently being treated, especially if diagnosed early. Cancer can be treated in several ways: surgery, chemotherapy, radiation therapy, immunotherapy, gene therapy, or a combination of these. Due to the relative inefficiency and very severe side effects of chemotherapy drugs, researchers and scientists have sought a new formulation of various compounds, especially metallic nanoparticles. ${ }^{[2-5]}$

In recent centuries, the application of nanotechnology has played an important role in the development of science. Nanoscience has shown that if we reduce the size to nanometers, unique properties such as optical properties, electrical conductivity, hardness, and chemical reaction will be obtained. Nanoparticles are widely used because of their high surface-to-volume ratio, small size, and excellent reactivity. One of the most important advances in nanotechnology is the production and application of nanoparticles in the biological sciences. ${ }^{[5-7]}$ Nanoparticles are generally effective in a wide variety of sectors that if their production is based on green chemistry, they have great applications in the fields of food, medicine, cosmetics and health. Nanoparticles centered on inorganic materials such as magnetic metals, their oxides and alloys, and semiconductors have the most studies and potential in biomedicine from diagnosis to treatment of diseases. ${ }^{[7-9]}$ The effects of nanoparticles should be predictable, controllable and get the desired results with minimal toxicity. Metallic nanoparticles used in treatment and diagnosis, in addition to being non-toxic, must be biocompatible and stable in vivo. Also, by making appropriate changes in the surface of metallic nanoparticles, they will have a wide range of applications by binding to biomolecules and various carriers to cross the cell membrane and target the desired part in the body. One of the important points in the production of nanoparticles is the use of cost-effective and efficient precursors. ${ }^{\left[{ }^{10-12]}\right.}$ There are three biological, chemical, and physical methods to synthesize the nanoparticles. Chemical and physical methods are time-consuming and costly. In addition, these methods use some toxic additive chemicals that cause adverse effects on medical applications by adsorption on the surface. Applying the principles of green chemistry has decreased the use of toxic compounds or hazardous solvents, provided optimal regeneration conditions and ameliorated materials for the chemical processes, and raised new sources for green synthesis. ${ }^{[13-16]}$ Therefore, one of the primary goals of green nanotechnology is to produce nanomaterials without harm to human health or environment, and to develop and design nanomaterials and products that are suitable solutions to environmental problems. The synthesis of nanoparticles by similar biological methods results in greater catalytic activity and limits the use of toxic and expensive chemicals. In biological methods, plant extracts, enzymes or proteins carrying natural resources are used to produce or stabilize nanoparticles. The nature of the materials used to make nanoparticles influences the shape, structure and morphology of these nanoparticles. ${ }^{[16-18]}$ Biological systems involved in the green synthesis of nanoparticles, plants and their derivatives, as well as microorganisms such as algae, fungi, and bacteria. Plant parts such as roots, leaves, stems, fruits, and tiny parts such as the kernel and skin of the fruit are suitable to synthesize the nanoparticles because their extracts are rich in phytochemicals that act as stabilizing and reducing substances. ${ }^{[6,8]}$ The use of natural plant extracts is a cheap and environmentally friendly process and does not require intermediate groups. Short time, no need for expensive equipment, precursors, high purity product and excellent quality without impurities are the features of this method. This is possible very quickly, at room temperature and pressure as well as easily on a large scale. Bio-reduction in the conversion of base metal ions is carried out by various plant metabolites such as alkaloids, phenolic compounds, terpenoids and coenzymes. ${ }^{[15-19]}$ 
Recently, scientists have used the anticancer effects of medicinal plants in several traditional medicines for synthesizing the gold nanoparticles containing natural compounds. So far, the anticancer effects of Tinospora cordifolia, Sophora subprostrata, Euphoria hirta, Barleria prionitis, Lubinus perennis, Maytenus boaria, Cephaelis acuminate, Phyllanthus niruri, Solanum seaforthianum, Boswellia serrate, Lavendula officinalis, and Cephalotaxus harringtonia drupacea have been proved. ${ }^{19}$ One of these plants is Verbascum thapsus L. In traditional medicine, $V$. thapsus is used for the treatment of tuberculosis, skin diseases, bruises, piles, frostbites, wounds, cuts, edema, swelling, inflammatory ailments in the respiratory tract, urinary disease, fever, bleeding of lungs and bowel, rectal prolapsed, gastrointestinal system ailments, diabetes, diarrhea, dysentery, infectious diseases, and especially lung diseases. ${ }^{20}$ It has chemical antioxidant components including $\beta$-carotene, lutein, zeaxanthin, cryptoxanthin, triterpene $A$, triterpene $B$, saikogenin $A$, veratric acid, $\beta$-spinasterol, 6-O- $\beta$-Dxylopyranosyl aucubin, thapsuine B, hydroxythapsuine thapsuine A, 3-O-fucopyranosylsaikogenin F, $\alpha$ tocopherol, $\gamma$-tocopherol, and $\delta$-tocopherol. ${ }^{20}$ Probably, the remedial properties of this species are related to the above compounds.

In the recent research, we decided to investigate the anti-human lung cancer effects of gold nanoparticles formulated by $V$. thapsus against well-differentiated bronchogenic adenocarcinoma, moderately differentiated adenocarcinoma of the lung, and poorly differentiated adenocarcinoma of the lung cell lines.

\section{EXPERIMENTAL}

\subsection{Material}

All materials used in the recent manuscript were achieved from Sigma-Aldrich Company of USA.

\subsection{Synthesis of AuNPs}

First, the leaves of the $V$. thapsus plant, after drying in the air, are pulverized using an electric grinder (model, Moulinex AR1066Q). $25 \mathrm{~g}$ of the leaves were soaked by maceration with distilled water and kept for at least three days with repeated stimulation to dissolve the solvent at room temperature. After three days, the mixture of extract and water was filtered using filter paper to separate the solids from the liquid. Finally, the excess solvent was evaporated and concentrated using a rotary evaporate. With the help of a freezer dryer (Scientific LTE UK, Ltd), it was completely dried and turned into a powder. Finally, the dry powder was stored in a sealed glass container and refrigerated and used to prepare different concentrations. ${ }^{[6,7]}$

The green synthesis of the AuNPs was initiated with a reaction mixture of $100 \mathrm{~mL}$ of $\mathrm{HAuCl}_{4} \times \mathrm{H}_{2} \mathrm{O}$ in the concentration of $1 \times 10^{-3} \mathrm{M}$ and $200 \mathrm{~mL}$ of aqueous extract solution of $V$. thapsus leaf $(20 \mu \mathrm{g} / \mathrm{mL}) \mathrm{in}$ the proportion 1:10 in a conical flask (Figure 1). The reaction mixture was kept under magnetic stirring for $12 \mathrm{~h}$ at room temperature. At the end of the reaction time, the dark red colored colloidal solution of Au was formed. The mixture was centrifuged at $10000 \mathrm{rpm}$ for $15 \mathrm{~min}$. The precipitate was triplet washed with water and centrifuged subsequently. ${ }^{[6]}$ For analyzing AuNPs, the common techniques of organic chemistry, i.e. FT-IR and UV-Vis. spectroscopy, FE-SEM, and TEM were used. AuNPs were primarily confirmed using UV-Vis spectroscopy at a scan range from 450-750 nm wavelength (Jasco V670 Spectrophotometer). The biomolecules involved in the reduction of AuNPs were detected by the FT-IR spectrophotometer (Shimadzu IR affinity.1). The morphological features in terms of shape and sizes were analyzed by FE-SEM (Fe-SEM ZEISS EVO18) and TEM (TEM FEITECNAI G2-20 TWIN) microscopic techniques.

\subsection{Assessment of the antioxidant potential of AuNPs by DPPH}

Free radicals are unstable atoms that have one or more unpaired electrons. These active species are very harmful due to their high reactivity. They are most often formed when oxygen molecules in the body split into separate unstable atoms. This process can turn into a chain reaction. Free radicals excessive production in the body causes cell damage and oxidative stress. Genetics and the environment affect the extent of free radical damage in individuals. These active molecules are produced as part of the body's natural biological processes. One of the 
most important free radicals is DPPH. DPPH is widely used to study the antioxidant activities of natural compounds and nanoparticles. ${ }^{[21,22]}$

In this method, the antioxidant activity of nanoparticles is measured for DPPH radical scavenging. The basis of the action is the reduction of the alcoholic solution of DPPH in the presence of hydrogen-giving antioxidants, especially phenolic compounds. To achieve the IC50 of the samples, 11 different concentrations of nanoparticles were prepared and the percentage of inhibitory versus concentration was used to plot. In practice, $300 \mu \mathrm{l}$ of $1 \mathrm{M}$ DPPH was combined with $100 \mu \mathrm{l}$ of diluted sample to a final volume of $2 \mathrm{ml}$ using methanol. After half an hour in the dark, the absorbance was read at $517 \mathrm{~nm}$ and the inhibitory percentage was obtained using the following formula:

$$
\text { Inhibition }(\%)=\frac{\text { Sample A. }}{\text { Control A. }} x 100
$$

In this formula, "Control A" shows the negative control of light absorption that lacks nanoparticles, and "Sample A" expresses the amount of light absorption of different concentrations of nanoparticles. ${ }^{[21,22]}$

\subsection{Measurement of cell toxicity of AuNPs}

Investigation of cell proliferation and survival is one of the most important and basic techniques in cell laboratories. This study requires accurate quantification of the number of living cells in the cell culture medium. Therefore, cell survival calculation methods are necessary to optimize cell culture conditions, evaluate cell growth factors, detect antibiotics and anticancer drugs, evaluate the toxic effects of environmental pollutants, and study apoptosis. Many methods can be used for such purposes, but indirect methods using fluorescent or dye (chromogenic) markers provide very fast large-scale methods. Among these methods, measurement of cell survival by MTT method (3- (4,5-dimethylthiazol-2-yl) -2,5-diphenyltetrazolium bromide) is the most widely used method. This method is a colorimetric method to study cell proliferation and survival, introduced in 1983 by Mossman. The method basis is based on mitochondrial activity. Mitochondrial activity in living cells is stable and therefore a raise or reduce in the living cells number is linearly related to mitochondrial activity. ${ }^{\left[{ }^{23]}\right.}$ MTT tetrazolium dye is revived in active cells. Mitochondrial dehydrogenases in living cells break the tetrazolium ring and yield NADPH and NADH, leading to forming a purple insoluble deposit called formazan. This precipitate can be dissolved by dimethyl sulfoxide or isopropanol. On the other hand, dead cells do not have this ability and therefore do not reveal a signal. Dye formation is used as a marker of living cells. The color intensity produced is measured at a 540 to $630 \mathrm{~nm}$ wavelength and is directly proportional to the living cells number. High safety and providing a colorimetric and non-radioactive system are important advantages of this method. This kit is very easy to use, has high sensitivity and accuracy and can detect less than 950 cells. On the other hand, it has high efficiency for measuring cell proliferation, survival and mortality, and its implementation method does not require time-consuming washing steps and transfer from one plate to another. Examples studied in this method are adhesive or suspended cells and proliferating or non-proliferating cells. ${ }^{[23]}$

In this experiment, the following cell lines have been used for investing the cytotoxicity and anti-human lung cancer effects of the $\mathrm{HAuCl}_{4}, V$. thapsus, and AuNPs using an MTT assay:

1) Normal cell line: HUVEC.

2) Well-differentiated bronchogenic adenocarcinoma cell line: HLC-1.

3) Moderately differentiated adenocarcinoma of the lung cell line: LC-2/ad.

4) Poorly differentiated adenocarcinoma of the lung cell line: PC-14.

Because nanoparticles is not soluble directly in 1640-RPMI medium and also the solvent of dimethyl sulfoxide nanoparticles (DMSO) itself has cytotoxic effects, to eliminate the effect of this substance on treated cells, its amount in the final solution is considered less than $1 \%$. Dimethyl sulfoxide is not toxic to concentrations less than $1 \%$ and the concentration of this solvent is important in this regard. For this purpose, $1000 \mu \mathrm{g}$ of nanoparticle was dissolved in $100 \mu \mathrm{l}$ of dimethyl sulfoxide solvent after weighing. Then $1 \mathrm{ml}$ of culture medium was added for better dissolution and finally the volume of solution was increased to $24 \mathrm{ml}$ using culture medium: Then, successive dilutions of this stock were used in the proportions of 1-1000 $\mu \mathrm{g} / \mathrm{ml}$. Eleven concentrations were used for the cell lines. ${ }^{[23]}$

In this study, 100 microliters of culture medium containing $10^{4}$ cells per plate 96 were placed. After 24 hours, incubation of concentrations of 1-1000 micrograms per milliliter of nanoparticles was added to the cells, and 
incubated for 24, 48, and 72 hours, respectively. After these times, $20 \mu$ of MTT plate with a concentration of 5 $\mathrm{mg} / \mathrm{ml}$ was added to each cell and incubated in the dark for another 4 hours. After some time, the MTT medium was carefully removed, and 200 microliters of acidified isopropanol were added to each plate to remove the purple formanes. After 15 minutes of incubation at room temperature, the light absorption of each well was read using an ELISA at $570 \mathrm{~nm}$ against a reference wavelength of $690 \mathrm{~nm}$. The findings were reported as cell survival and IC50 (concentration that inhibits cell growth up to $50 \%$ ) based on the concentration curve $(\mu \mathrm{g} / \mathrm{ml})$. ${ }^{[23]}$

It should be noted that the effect of each concentration of the nanoparticles on cell lines was investigated in five independent experiments. According to the values of light absorption obtained by the ELISA reader, the percentage of growth inhibition related to each concentration was calculated using the following formula:

$$
\text { Cell viability }(\%)=\frac{\text { Sample A. }}{\text { Control A. }} \times 100
$$

Finally, linear regression was done to gain IC50, which indicates the nanoparticles concentration, which causes $50 \%$ cancer cell growth inhibition. Using the curve, the line equation for cancer cells was obtained, respectively, then by replacing 50\% inhibition in the equation, the IC50 value for cancer cells was obtained. ${ }^{[23]}$

\subsection{Statistical analysis}

SPSS statistical software version 22 was used for data analysis and the findings were determined as the mean standard deviation of 5 replications. Data were analyzed using one-way analysis of variance and Duncan post hoc test and the significance level in the test was considered 0.05 .

\section{RESULTS AND DISCUSSION}

Recently, the anti-angiogenic and anti-cancer properties of gold nanoparticles have been determined and the findings have revealed that gold nanoparticles can be used as a unique anti-cancer supplement. But the organic solvents used to produce these nanoparticles are toxic and can have devastating environmental effects. Hence there is a great tendency to use healthy methods for synthesizing gold nanoparticles. Recently, studies have begun under the title Green Chemistry, which seeks an environmentally friendly way for nanoparticles synthesis [2426]. In recent years, gold nanoparticles have been synthesized extracellularly using various plant and microbial extracts. In addition, many studies are underway to investigate the antibacterial, antioxidant and anti-tumor properties of these natural products $[25,26]$. In this regard, a study assessed the antibacterial activities of gold nanoparticles synthesized biologically [26,27]. Another study evaluated the anticancer, antibacterial, and antioxidant properties of gold nanoparticles yielded by plant extract $[27,28]$. The anti-inflammatory, antioxidant and antimicrobial effects of metallic nanoparticles green-synthesized by medicinal plants are well known [2830]. It also affects a range of molecular targets and signaling pathways, such as NF-JB, AKT/mTOR, and HIF$1 \mathrm{~A}$, and as a result, it plays a role in inhibiting cancer cell proliferation, metastasis, angiogenesis and also inducing apoptosis [30]. Previous studies have also shown that metallic nanoparticles containing medicinal plants cause deformity and perforation of cancer cells, resulting in their death $[29,30]$.

\subsection{UV-visible spectroscopy of gold nanoparticles synthesized using $V$. thapsus}

UV-Vis is based on the irradiation of ultraviolet and visible photons on the sample and measures the rate of passage or absorption of matter at different wavelengths in the range of 200 to $1100 \mathrm{~nm}$. It is possible to measure the spectrum for samples in solution, solid as well as thin layers. The size of solid samples should be larger than $20 \mathrm{~mm}$. This test is not possible for powder samples. One of the important applications of UV device is to determine the concentration of the unknown solution. By having the original sample and its solvent and making 
several solutions with different percentages and drawing a calibration diagram based on the calculation of the maximum land, the concentration of the unknown solutions can be calculated. ${ }^{[14,15]}$

UV-Vis spectroscopic analysis showed the presence of an absorption peak at $548 \mathrm{~nm}$ which confirmed the formation of the gold nanoparticles (Figure 2). In agreement with our study, Shahriari et al. (2019) reported Allium noeanum Reut. ex Regel aqueous extract synthesized gold nanoparticles with a peak at $542 \mathrm{~nm}$ in the UV-Visible spectrum. ${ }^{15}$ Zhaleh et al. (2019) reported the absorbance at $528 \mathrm{~nm}$ for gold nanoparticles synthesized by Gundelia tournefortii L.. ${ }^{14}$ Zangneh et al. (2019) studied Falcaria vulgaris aqueous extracts mediated synthesis of gold nanoparticles. Absorption in the spectrum was noted in the wavelength of $535 \mathrm{~nm} .{ }^{6}$ Hemmati et al. (2019) reported Thymus vulgaris leaf aqueous extract mediated gold nanoparticles and absorption peak was observed at $532 \mathrm{~nm}{ }^{7}$ These reports support the results of the current work.

Figure 2

\subsection{TEM analysis of gold nanoparticles synthesized using $V$. thapsus}

TEM (transmission electron microscope) is used for determining the structure and morphology of materials. TEM transmission electron microscope products enable microstructural studies with high resolution and high magnification such as studies of crystal structures, symmetry, orientation and crystal defects. TEM and SEM microscopes differ in how the beam passes and the information obtained from the sample. Scanning microscopes take pictures of the sample surface, while passing microscopes take pictures of the inside of the sample. The resolution and magnification of electron microscopes are higher than those of scanning electron microscopes. The electron beams in the scanning electron microscope scan the surface of the sample point-by-point, but the TEM microscope beams hit and pass through the entire sample. In addition, sample preparation for the SEM microscope is easier than for the TEM microscope. ${ }^{[14,15]}$

TEM is the other test for determining the morphology and size of metallic nanoparticles. In our study, the range size of the nanoparticles (19-24 nm) calculated through TEM images (Figure 3). Furthermore, the histogram plot from the TEM image showed the particle size distribution of biosynthesized gold nanoparticles ranges of 16 to $22 \mathrm{~nm}$. In the previous studies, the size of gold nanoparticles formulated by aqueous extract of medicinal plants had been calculated in the ranges of $10-45 \mathrm{~nm}$ with the shape of spherical. ${ }^{6,7,14,15}$ These reports support the results of the current work.

Figure 3

\subsection{FT-IR analysis of gold nanoparticles synthesized using $V$. thapsus}

FT-IR (Fourier Transform Infrared) has been a suitable technique for analyzing materials in the laboratory. An infrared spectrum represents the fingerprint of the sample under test with absorption peaks, which depends on our vibrational frequencies between the atomic bonds of that material. Since each substance has its own atomic bonds, no two compounds with the same infrared spectrum are alike. Hence, infrared spectroscopy can be effective in better identification (qualitative analysis) of different types of materials. Also, the peak sizes are in the range indicating the amount of material present. Advanced software algorithms make this spectroscopy a great tool for quantitative analysis. ${ }^{[14,15]}$

In FT-IR test, the antioxidant and secondary compounds are determined based on several peaks in special wavelengths. The IR spectra investigated for the gold nanoparticles revealed the absorption peaks at (I) $3287 \mathrm{~cm}^{-}$ ${ }^{1}$ (OH group of alcohols and phenols); (II) $1623 \mathrm{~cm}^{-1}$ (C-O group of carboxylic acid group); (III) $1383 \mathrm{~cm}^{-1}$ (C=O stretching of carboxylic acid group); (IV) $1038 \mathrm{~cm}^{-1}$ (C-OH vibrations of the protein/polysaccharide). ${ }^{6,7,14,15}$ In 
the recent study, the analysis of the IR spectra of the gold nanoparticles revealed the peaks at 3473, 1640, 1337, 1086, and $541 \mathrm{~cm}^{-1}$ related to the $\mathrm{OH}, \mathrm{C}-\mathrm{O}, \mathrm{C}=\mathrm{O}, \mathrm{C}-\mathrm{OH}$, and Au-O respectively (Figure 4).

Figure 4

\subsection{FE-SEM analysis of gold nanoparticles synthesized using $V$. thapsus}

The SEM device is one of the most powerful tools used in various fields, including nanotechnology, which uses electron bombardment to produce images of objects as small as 10 nanometers. The bombardment of the sample causes positively charged electrons to be released from the sample to the plate, where these electrons become signals. ${ }^{[14,15]}$

FE-SEM analysis is one of the common chemistry tests for determining the morphology and size of several materials such as metallic nanoparticles. In the present study, the FE-SEM image of gold nanoparticles synthesized using $V$. thapsus leaf aqueous extract is shown in Figure 5. The gold nanoparticles appeared as an agglomerated structure. The hydroxyl groups present in $V$. thapsus could be responsible for agglomeration. ${ }^{31}$ Also, FE-SEM images indicated the range size of 16-22 $\mathrm{nm}$ and the shape of spherical for gold nanoparticles. Many similar observations are noted by Zhaleh et al. (2019), ${ }^{14}$ Zangneh et al. (2019), ${ }^{6}$ Hemmati et al. (2019), ${ }^{7}$ and Shahriari et al. (2019). ${ }^{15}$

Figure 5

\subsection{Antioxidant properties of gold nanoparticles synthesized using $V$. thapsus}

Oxidation is the electrons transfer from an atom and is the aerobic life and metabolism part of living organisms. Oxygen is the receptor for electrons in the electron transport system, which yields energy from ATP (Adenosine triphosphate) in the body. Under certain conditions, oxygen may become a single electron and release free radicals. When oxygen becomes a single electron, it is called reactive oxygen species (ROS). Oxidative loss to proteins, DNA, and other macromolecules is one of the internal causes of degenerative diseases such as aging, cardiovascular disease, cancer, immune system deficiency, cataracts, and abnormal brain function. Single oxygen, high-energy, mutagenic oxygen, can be produced by lipid peroxidation by the transmission of energy from light or the respiratory tract of neutrophils. ${ }^{[14,15]}$ Some free radicals have positive roles such as regulating cell growth, phagocytosis, energy production, intracellular signals, or the important biological compounds synthesis. Antioxidants produced in the body fight free radicals with two systems: enzymatic defense and non-enzymatic defense. Superoxide dismutase, catalase, and glutathione peroxidase metabolize lipid peroxide, hydrogen peroxide, and superoxide and prevent the production of toxic hydroxyl radicals. ${ }^{[32,33]}$ In non-enzymatic defense, there are two classes of fat-soluble antioxidants (such as carotenoids and vitamin E) and water-soluble (glutathione and vitamin C) that trap free radicals. These two systems help neutralize oxidants. However, oxidants can escape from antioxidants and damage tissues. In this case, the activated antioxidant repair system (which is the enzymes lipase, protease, transferase and DNA repair enzymes), counteract the oxidant effects. However, due to deficiencies in the production of antioxidants in the body or due to physiopathological factors and situations (such as smoking, air pollution, UV radiation, diets containing high unsaturated fatty acids, inflammation, ischemia, bleeding, etc) that ROS are yielded in large quantities at the wrong place and time, oral antioxidants are needed to counteract the oxidative damage cumulative effects. ${ }^{[33-36]}$

In the present experiment, the antioxidant effects of the gold nanoparticles synthesized using $V$. thapsus leaf aqueous extract were evaluated by DPPH assay revealed concentration-dependent effects i.e., an increase in the concentration of the gold nanoparticles leads to an increase in antioxidant activities. In the concentrations of studied, the best result was seen in the high concentration or $1000 \mu \mathrm{g} / \mathrm{mL}$ (Figure 6). Comparative analysis of the 
individual antioxidant assays showed significant variations in the exertion of radical scavenging effects. Among all materials tested $\left(\mathrm{HAuCl}_{4}, \mathrm{~V}\right.$. thapsus, and AuNPs), the gold nanoparticles indicated more excellent inhibition effects against DPPH. In contrast, standard (butylated hydroxytoluene) demonstrated lower antioxidant effects compared to the gold nanoparticles.

The IC50 of $V$. thapsus, butylated hydroxytoluene, and AuNPs were 407, 256, and $209 \mu \mathrm{g} / \mathrm{mL}$, respectively (Table 1).

\section{Figure 6}

Table 1

The reason behind the antioxidant activity of green or biosynthesized nanoparticles could be due to the presence of metabolites compounds such as phenolic compounds, flavonoids, carbohydrates, and other sugar substances. ${ }^{31-}$ ${ }^{36}$ Also, many researchers reported phenolic and flavonoids attached to the nanoparticles exhibited the antioxidant activity. Previously has been indicated that $V$. thapsus is rich in antioxidant compounds such as $\beta$-carotene, lutein, zeaxanthin, cryptoxanthin, triterpene A, triterpene B, saikogenin A, veratric acid, $\beta$-spinasterol, 6-O- $\beta$-Dxylopyranosyl aucubin, thapsuine $\mathrm{B}$, hydroxythapsuine thapsuine A, 3-O-fucopyranosylsaikogenin F, $\alpha-$ tocopherol, $\gamma$-tocopherol, and $\delta$-tocopherol. ${ }^{20}$ Several studies were carried out in the nanotechnology field using various medicinal plants, but still, no report is available on gold nanoparticles synthesized using $V$. thapsus leaf aqueous extract.

\subsection{Cytotoxicity and anti-human lung cancer potentials of gold nanoparticles synthesized using $V$. thapsus}

Nanotechnology is a new branch of science with a wide range of applications and nanoparticles with different compositions and sizes, shapes and surface chemical properties can have different biological and biomedical applications. Reducing the size of materials at the nanoscale can often cause electrical, magnetic, structural, morphological, and chemical changes. Nanoparticles typically have a higher percentage of atoms on their surface, which increases surface reactions. ${ }^{[18]}$ Proper design of nanomaterials can be used to target specific cancer cells. Nanoparticles have antibacterial and magnetic properties by penetrating microorganisms due to their high surfaceto-volume ratio and small size. Also, due to their photocatalytic, catalytic and ionic properties, they are widely used in the fight against human pathogenic microbes, bacteria, fungi and viruses. ${ }^{[37-39]}$ Researchers have shown that gold nanoparticles kill Schwann cells by releasing $\mathrm{Au}^{+}$. A study has shown that concomitant use of gold and doxorubicin reduces the reproductive toxicity of doxorubicin. ${ }^{[14,15]}$ By producing active bases such as oxygen ions and hydroxides, gold nanoparticles disrupt the metabolism, proliferation and respiration of microorganisms by destroying organic structures and strongly interacting with enzymes and proteins in the electron transfer system, and it can kill more than 650 types of gram-negative and gram-positive bacteria resistant to common antibiotics in vitro up to $99.9 \% .^{[37-39]}$ Metallic nanoparticles in cell cultures and human tissues yield toxins that raise inflammatory products such as cytokines and oxidative stress, ultimately leading to cell death. Larger nanoparticles are seen by the nuclei and mitochondria, causing mutations in DNA, destruction of the mitochondrial structure, and even cell death. ${ }^{[40-42]}$ Solubility and density, surface baroelectricity, surface structure, shape, chemical composition, and size and dimensions are the key factors in determining the toxicity of nanoparticles. The exact effect of gold and gold nanoparticles on cancer cells is not fully understood, but increasing ROS production is one of the possible mechanisms. ${ }^{[41,42]}$ When nanoparticles are in contact with cancer cells, the cellular defense mechanism is activated to minimize damage. But, if the ROS production stimulation inside the cell by nanoparticles exceeds the cell antioxidant defense capacity, the cells are destroyed during the process of apoptotic cell death. ${ }^{[37,42]}$ The electrostatic interaction of nanoparticles causes them to be absorbed into target cells. Positively charged nanoparticles are attracted to cancer cells with a high percentage of anionic phospholipids and certain groups of charged proteins and carbohydrates on their outer surface. ${ }^{\text {[40-42] }}$ 
In the present experiment, the treated cells with several concentrations of the present $\mathrm{HAuCl}_{4}, V$. thapsus, and AuNPs were examined by MTT test for $48 \mathrm{~h}$ regarding the cytotoxicity properties on normal (HUVEC) and human lung cancer cell lines i.e., well-differentiated bronchogenic adenocarcinoma (HLC-1), moderately differentiated adenocarcinoma of the lung (LC-2/ad), and poorly differentiated adenocarcinoma of the lung (PC-14) (Figures 710; Table 2).

The absorbance rate was determined at $570 \mathrm{~nm}$, which indicated extraordinary viability on normal cell line (HUVEC) even up to $1000 \mu \mathrm{g} / \mathrm{mL}$ for $\mathrm{HAuCl}_{4}$, V. thapsus, and AuNPs.

In the case of human lung cancer cell lines, the viability of them reduced dose-dependently in the presence of $\mathrm{HAuCl}_{4}, V$. thapsus, and AuNPs. The IC50 of V. thapsus, and AuNPs against HLC-1 cell line were 500 and 308 $\mu \mathrm{g} / \mathrm{mL}$, respectively; against LC-2/ad cell line were 462 and $287 \mu \mathrm{g} / \mathrm{mL}$, respectively; and against PC-14 cell line were 396 and $209 \mu \mathrm{g} / \mathrm{mL}$, respectively. The best result of anti-human lung cancer property of gold nanoparticles against the above cell lines was seen in the case of the poorly differentiated adenocarcinoma of the lung (PC-14) cell line.

Likely the significant anti-human lung cancer potentials of gold nanoparticles synthesized by $V$. thapsus leaf aqueous extract against human lung cancer cell lines are linked to their antioxidant activities. The similar researches have revealed the antioxidant materials such as metallic nanoparticles especially gold nanoparticles and ethno medicinal plants reduce the volume of tumors by removing free radicals. ${ }^{[39]}$ In detail, the high presence of free radicals in the normal cells make many mutation in their DNA and RNA, destroy their gene expression and then accelerate the proliferation and growth of abnormal cells or cancerous cells. ${ }^{[40,41]}$ The free radicals high presences in all cancers such as breast, gallbladder, stomach, rectal, liver, gastrointestinal stromal, esophageal, bile duct, small intestine, pancreatic, colon, parathyroid, thyroid, bladder, prostate, testicular, fallopian tube, vaginal, ovarian, hypopharyngeal, throat, lung, and skin cancers indicate significant role of these molecules in making angiogenesis and tumorigenesis. ${ }^{[41,42]}$ Many researchers reported that gold nanoparticles synthesized by ethno medicinal plants have remarkable role in the removing free radicals and growth inhibition of all cancerous cells. ${ }^{[38-42]}$

Figure 7

Figure 8

Figure 9

Figure 10

Table 2

\section{Acknowledgement:}

This project was supported by Researchers Supporting Project number (RSP-2021/230) King Saud University, Riyadh, Saudi Arabia.

\section{CONCLUSIONS}

In the present study, Verbascum thapsus L. leaf collected was applied for biosynthesizing gold nanoparticles as a safe and suitable material. After gold nanoparticles synthesizing, they were characterized by TEM, FE-SEM, UV Vis., and FT-IR. The above analyses revealed that gold nanoparticles were synthesized as the best possible form. In the FT-IR test, the presence of many antioxidant compounds with related bonds caused the excellent condition 
for reducing of gold in the gold nanoparticles, so that the antioxidant properties of gold nanoparticles was the better than the BHT as a positive control. Gold nanoparticles showed significant anti-human lung activities against well-differentiated bronchogenic adenocarcinoma (HLC-1), moderately differentiated adenocarcinoma of the lung (LC-2/ad), and poorly differentiated adenocarcinoma of the lung (PC-14) cell lines. It looks these nanoparticles may be administrated as a chemotherapeutic drug for the treatment of several types of lung cancers especially well-differentiated bronchogenic adenocarcinoma, moderately differentiated adenocarcinoma of the lung, and poorly differentiated adenocarcinoma of the lung.

\section{REFERENCES}

[1] M.J. Thun, L.M. Hannan, L.L. Adams-Campbell, PLoS Med. 2008, 5, e185.

[2] R. Taylor, F. Najafi, A. Dobson, Int J Epidemiol. 2007, 36, 1048-1059.

[3] S.S. Hecht, Int J Cancer. 2012, 131, 2724-2732

[4] L.G. Collins, C. Haines, R. Perkel, R.E. Enck, Am Fam Physician. 2007, 75, 56-63.

[5] N.A. Alsharairi, Nutrient. 2019, 11, 725.

[6] A. Zangeneh, M.M. Zangeneh, Appl Organometal Chem. 2019, 33, e5290. DOI:10.1002/aoc.5290.

[7] S. Hemmati, Z. Joshani, A. Zangeneh, M.M. Zangeneh, Appl Organometal Chem. 2019, 33, e5267. DOI:10.1002/aoc.5267.

[8] R. W. Raut, N. S. Kolekar, J. R. Lakkakula, V. D. Mendhulkar, S. B. Kashid, Nano-Micro Lett. 2010, $2,106$. [9] R. S. Varma, Curr Opin Chem Eng. 2012, 1, 123.

[10] K. D. Arunachalam, S. K. Annamalai, S. Hari, Int J Nanomedicine. 2003, 8, 1307-1315.

[11] L. Sintubin, W. D. Windt, J. Dick, J. Mast, D. van der Ha, W. Verstraete, N. Boon, Appl Microbiol Biotechnol. 2009, 6, 741-749.

[12] V. Ball, Front. Bioeng Biotechnol. 2018, 6, 109.

[13] (a) M.M. Zangeneh, Appl Organometal Chem. 2019, 33, e5295. DOI:10.1002/aoc.5295. (b) G. Mohammadi, M.M. Zangeneh, A. Zangeneh, Z.M. Siavosh Haghighi, Appl Organometal Chem. 2019, 33, e5136. DOI:10.1002/aoc.5136.

[14] M. Zhaleh, A. Zangeneh, S. Goorani, N. Seydi, M.M. Zangeneh, R. Tahvilian, E. Pirabbasi, Appl Organometal Chem. 2019, 33, e5015.

[15] M. Shahriari, S. Hemmati, A. Zangeneh, M.M. Zangeneh, Appl Organometal Chem. 2019, 33, e5189. DOI: 10.1002/aoc.5189.

[16] M.M. Zangeneh, S. Saneei, A. Zangeneh, R. Toushmalani, A. Haddadi, M. Almasi, A. Amiri-Paryan, Appl Organometal Chem. 2019, 33, e5216. DOI: 10.1002/aoc.5216.

[17] P. Singh, S. Pandit, V. R. S. S. Mokkapati, A. Garg, V. Ravikumar, I. Mijakovic, Int J Mol Sci. 2018, 19, 1979.

[18] G. Peng, U. Tisch, O. Adams, M. Hakim, N. Shehada, Y.Y. Broza, S. Billan, R. Abdah-Bortnyak, A. Kuten, H. Haick, Nat Nanotechnol. 2009, 4, 669-673.

[19] A. Soni, R. Krishnamurthy, Indian J Plant Sci. 2013, 2, 117-125.

[20] M. Riaza, M. Zia-Ul-Haqb, H. Z. E. Jaafarc, Rev Bras Farmacogn, 2013, 23, 948-959.

[21] P. Tveden-Nyborg, T.K. Bergmann, J. Lykkesfeldt, Basic Clin Pharmacol Toxicol 2018;123:233-35

[22] S.J. Hosseinimehr, A. Mahmoudzadeh, A. Ahmadi, S. A. Ashrafi, N. Shafaghati, N. Hedayati, Cancer Biother Radiopharm. 2011, 26, 325-329.

[23] V. Arulmozhi, K. Pandian, S. Mirunalini, Colloids Surf B Biointerfaces. 2013, 110, 313-320.

[24] C. Pereira, A. M. Pereira, C. Fernandes, M. Rocha, R. Mendes, M. P. Fernández-García, A. Guedes, P. B. Tavares, J. M. Grenèche, J. P. Araújo, C. Freire, Chem Mater, 2012, 24, 1496-1504.

[25] S. P. Deshmukh, S. M. Patil, S. B. Mullani, S. D. Delekar, Mat Sci Eng C, 2019, 97, 954-965.

[26] A. A. Shah, F. Hasan, A. Hameed, S. Ahmed, Biotech Adv, 2008, 26, 246-265.

[27] A. E. D. M. van der Heijden, Chem Eng J. 2018, 350, 939-948.

[28] S. Jin, C. Wu, Z. zhong Ye, Y. Ying, Sen Act B Chem, 2019, 283, 18-34.

[29] R. Kumar, A. Umar, G. Kumar, H. S. Nalwa, Ceramics Inter, 2017, 43, 3940-3961.

[30] S. Mehwish, A. Islam, I. Ullah, A. Wakeel, M. Qasim, M. AliKhan, A. Ahmad, N. Ullah, Biocat Agri Biotech, 2019, 19, 101117. 
[31] J. Ramyadevi, K. Jeyasubramanian, A. Marikani, G. Rajakumar, A. A. Rahuman, Mater lett. 2012, 71, 114116.

[32] D. D. Gultekin, A. A. Gungor, H. Onem, A. Babagil, H. Nadaroglu, J Turk Chem Soc A: Chem. 2016, 3 , 623-36.

[33] D. Rehana, D. Mahendiran, R. S. Kumar, A. K. Rahiman, Biomed Pharmacother. 2017, 89, 1067-1077. [34] M. Del Mar Delgado-Povedano, V. S. De Medina, J. Bautista, F. Priego-Capote, M. D. De Castro MD, J Function Foods. 2016, 24, 403-19.

[35] S. C. Jeong, S. R. Koyyalamudi, Y. T. Jeong, C. H. Song, G. Pang, J Med Food. 2012, 1, 58-65.

[36] R. Sankar, R. Maheswari, S. Karthik, K. S. Shivashangari, V. Ravikumar, Mat Sci Eng C. 2014, 44, 234239.

[37] F. Namvar, H.S. Rahman, R. Mohamad, J. Baharara, M. Mahdavi, E. Amini, M.S. Chartrand, S.K. Yeap. Int J Nanomedicine. 2014, 19, 2479-88.

[38] L. Katata-Seru, T. Moremedi, O.S. Aremu, I. Bahadur, J Mol Liq. 2018, 256, 296-304.

[39] S. Sangami, B. Manu, Environ Technol Innov. 2017, 8, 150-163.

[40] N. Beheshtkhoo, M.A.J. Kouhbanani, A. Savardashtaki, A.M. Amani, S. Taghizadeh, Appl Phys A. 2018, 124, 363-369.

[41] I.A. Radini, N. Hasan, M.A. Malik, Z. Khan, J Photochem Photobiol B. 2018, 183, 154-163.

[42] G. Oganesvan, A. Galstyan, V. Mnatsakanyan, R. Paronikyan, Y.Z. Ter-Zakharyan, Chem Nat. 1991, 27, 247-247. 
Table 1. The IC50 of $\mathrm{HAuCl}_{4}, V$. thapsus, AuNPs, and BHT in the antioxidant test.

\begin{tabular}{|l|l|l|l|l|}
\hline & HAuCl $_{\mathbf{4}}(\boldsymbol{\mu g} / \mathbf{m L})$ & $V$. thapsus $(\boldsymbol{\mu g} / \mathbf{m L})$ & AuNPs $(\boldsymbol{\mu g} / \mathbf{m L})$ & $\begin{array}{l}\text { BHT } \\
(\boldsymbol{\mu g} / \mathbf{m L})\end{array}$ \\
\hline IC50 against DPPH & - & 407 & 209 & 256 \\
\hline
\end{tabular}


Table 2. The IC50 of $\mathrm{HAuCl}_{4}, V$. thapsus, and AuNPs in the cytotoxicity test.

\begin{tabular}{|l|l|l|l|}
\hline & $\begin{array}{l}\text { HAuCl } \\
(\boldsymbol{\mu g} / \mathbf{m L})\end{array}$ & $\begin{array}{l}\boldsymbol{V} \text { thapsus } \\
(\boldsymbol{\mu g} / \mathbf{m L})\end{array}$ & AuNPs $(\boldsymbol{\mu g} / \mathbf{m L})$ \\
\hline IC50 against 'HUVEC' & - & & - \\
\hline IC50 against 'HLC-1' & - & 500 & 308 \\
\hline IC50 against 'LC-2/ad' & - & 462 & 287 \\
\hline IC50 against 'PC-14' & - & 396 & 209 \\
\hline
\end{tabular}




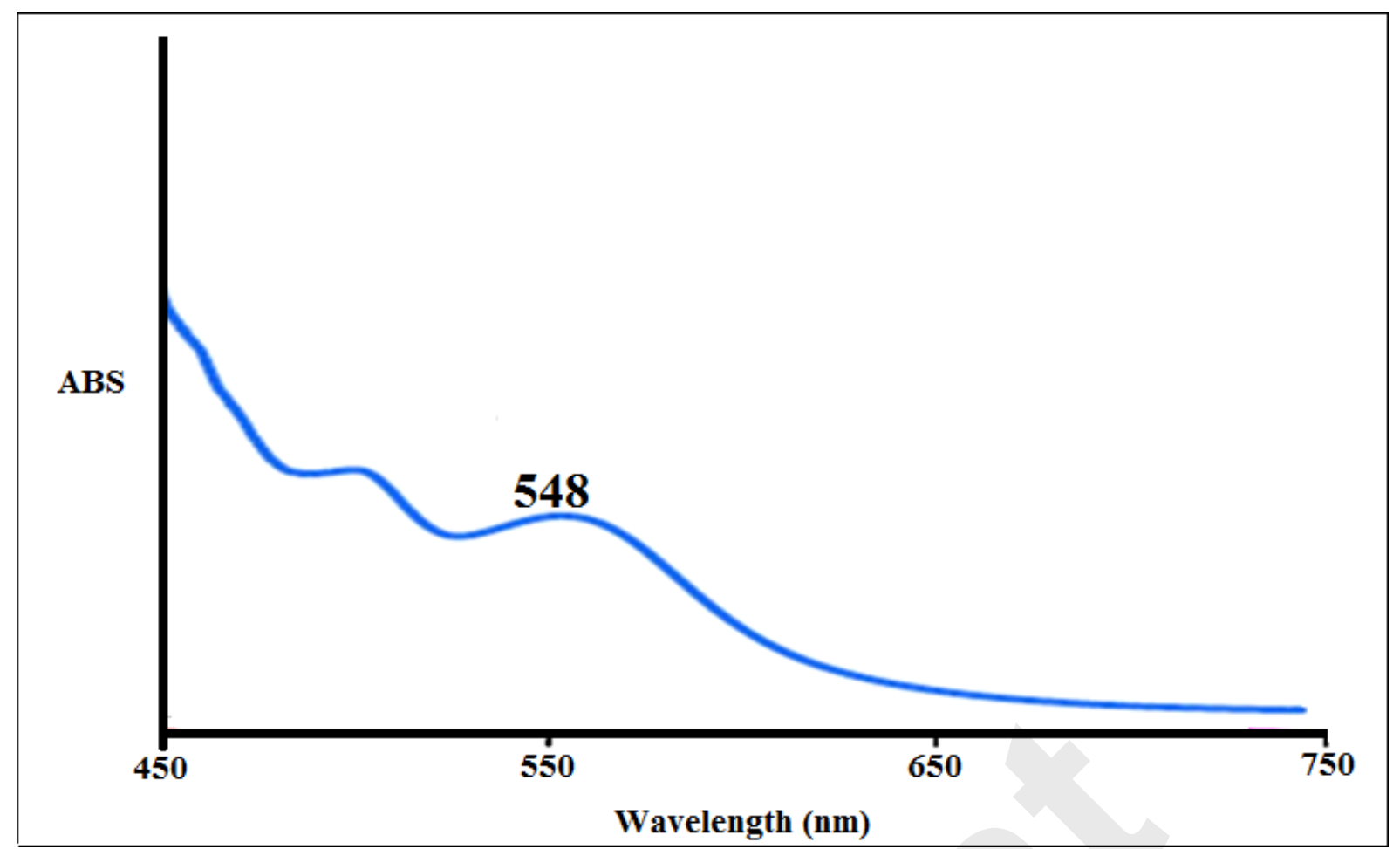

Figure 1. The UV-Vis spectrum of biosynthesized gold nanoparticles. 


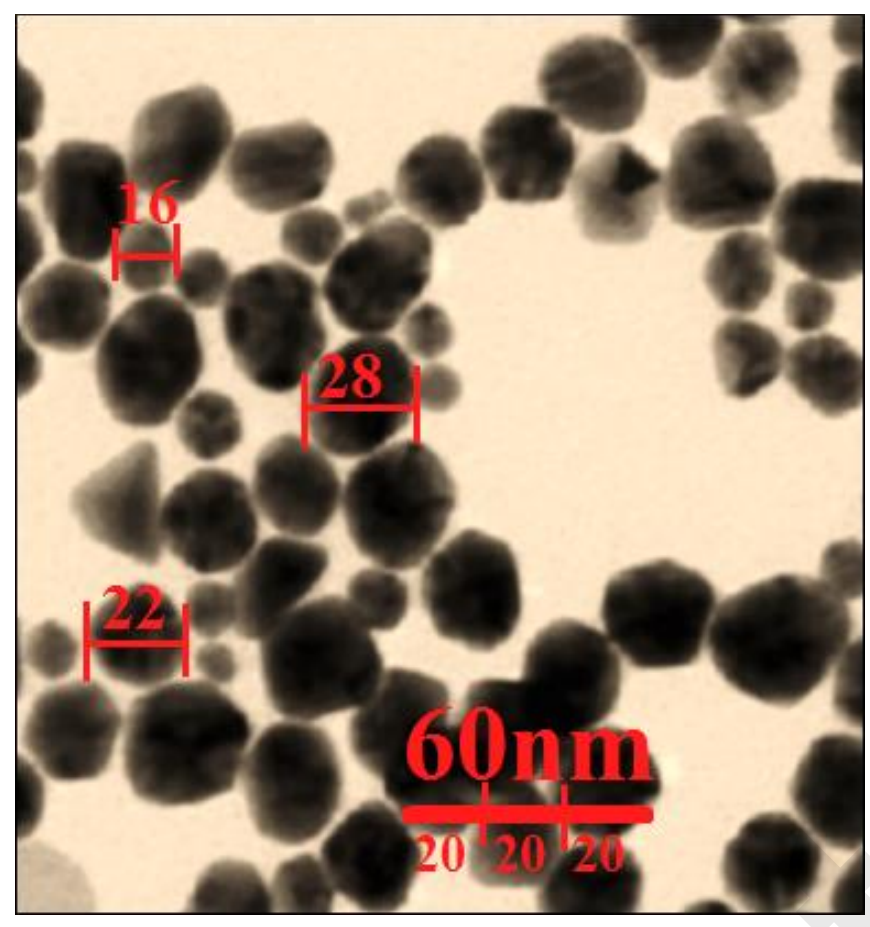

Figure 2. TEM image of gold nanoparticles. 


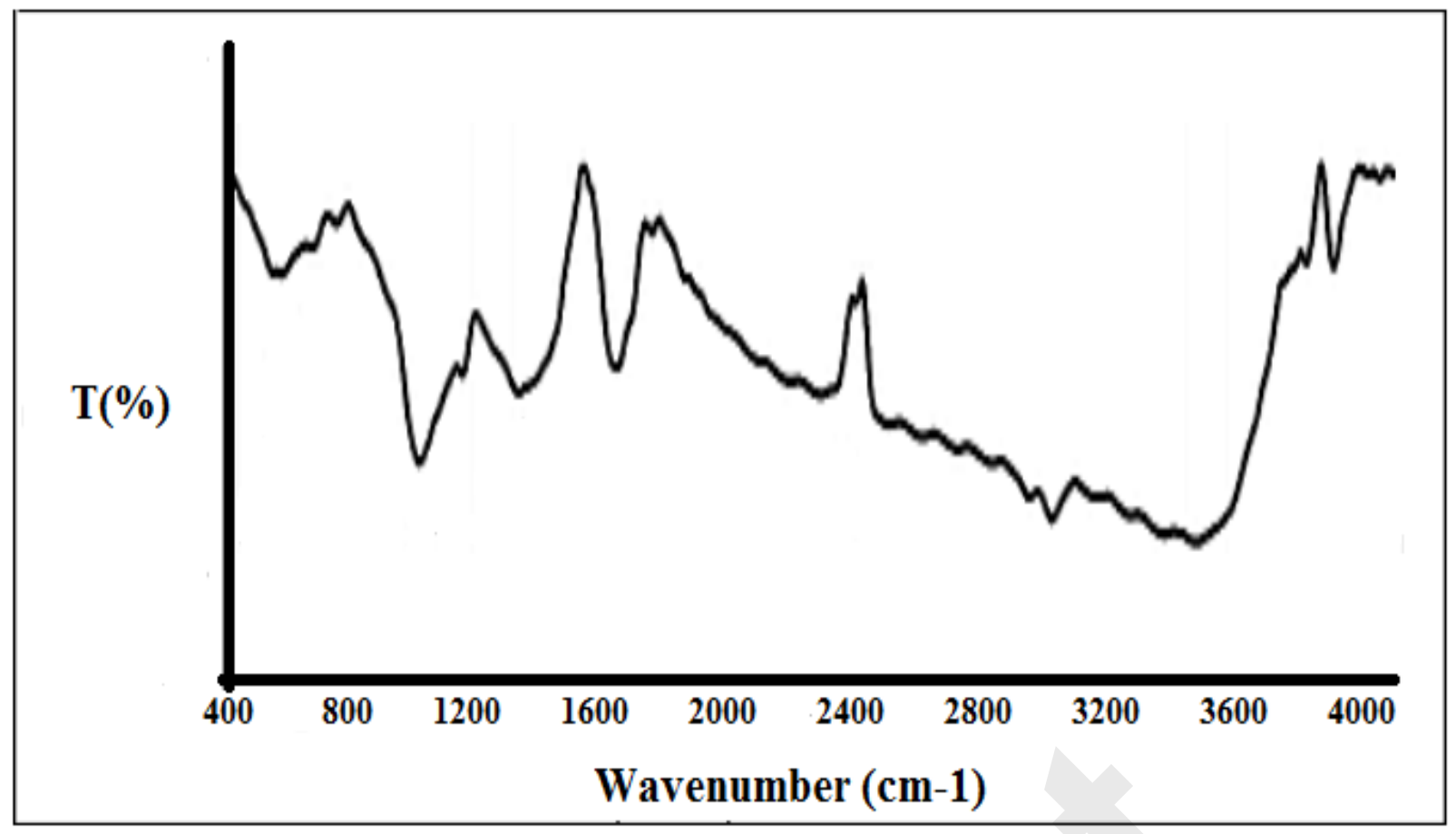

Figure 3. FT-IR spectra of biosynthesized gold nanoparticles. 


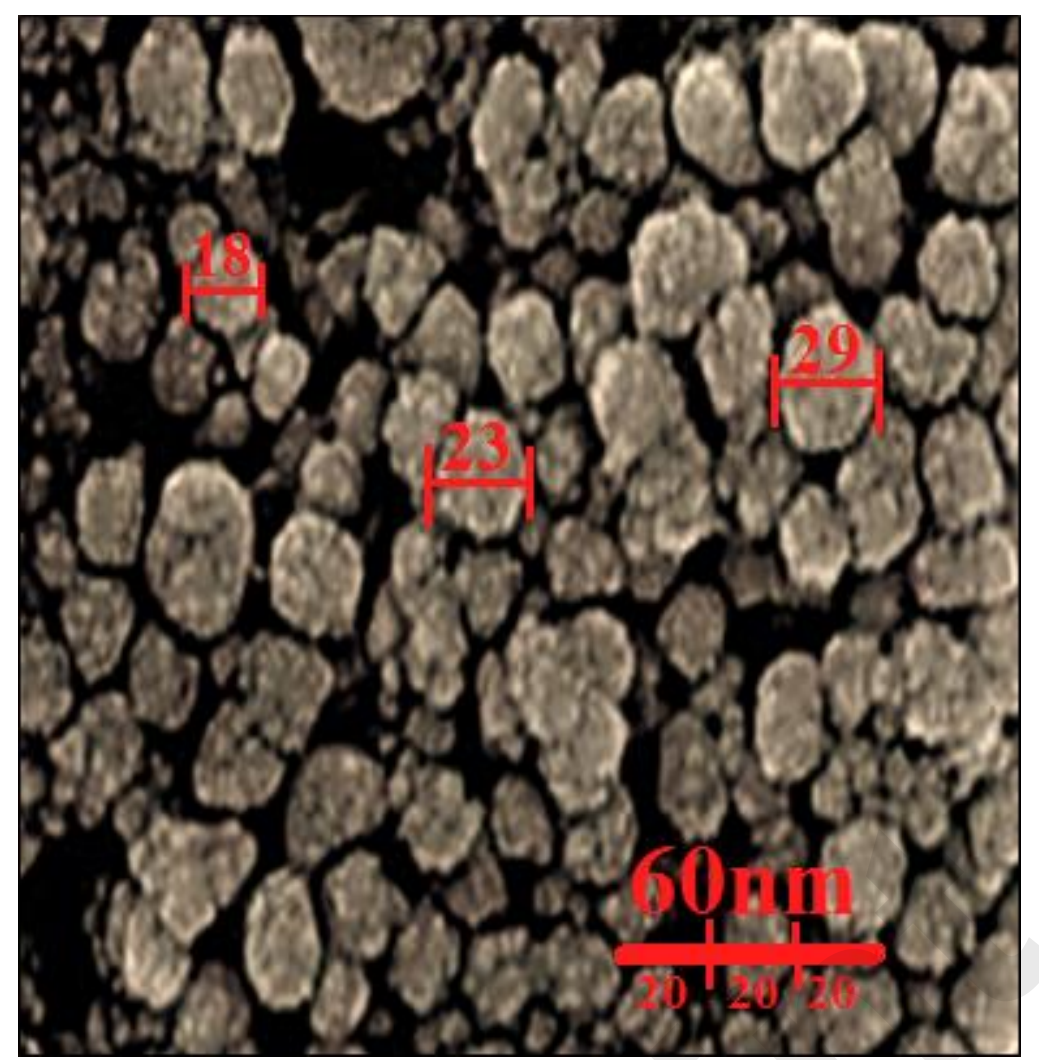

Figure 4. FE-SEM image of gold nanoparticles. 


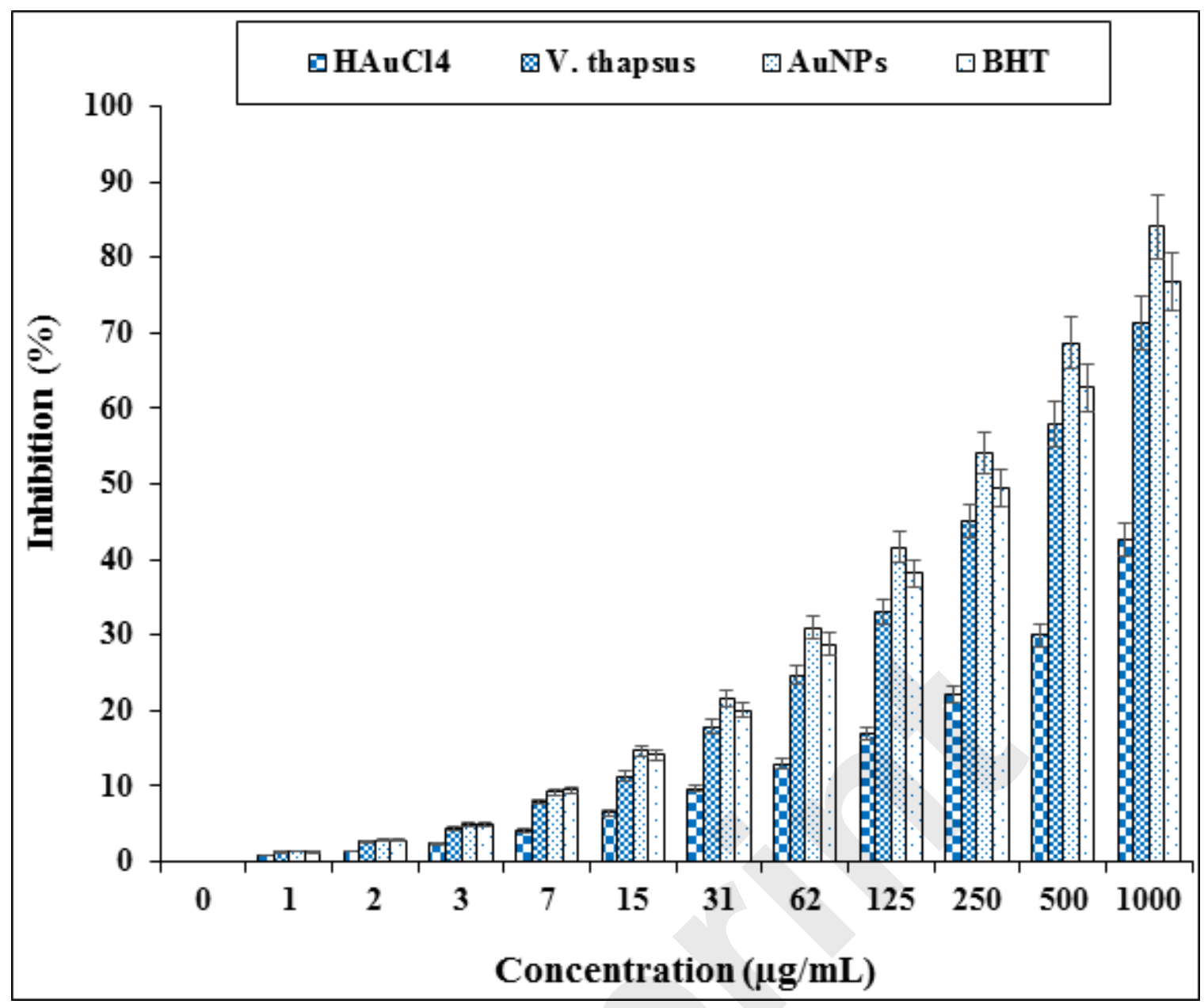

Figure 5. The antioxidant properties of $\mathrm{HAuCl}_{4}, V$. thapsus, AuNPs, and BHT against DPPH. 


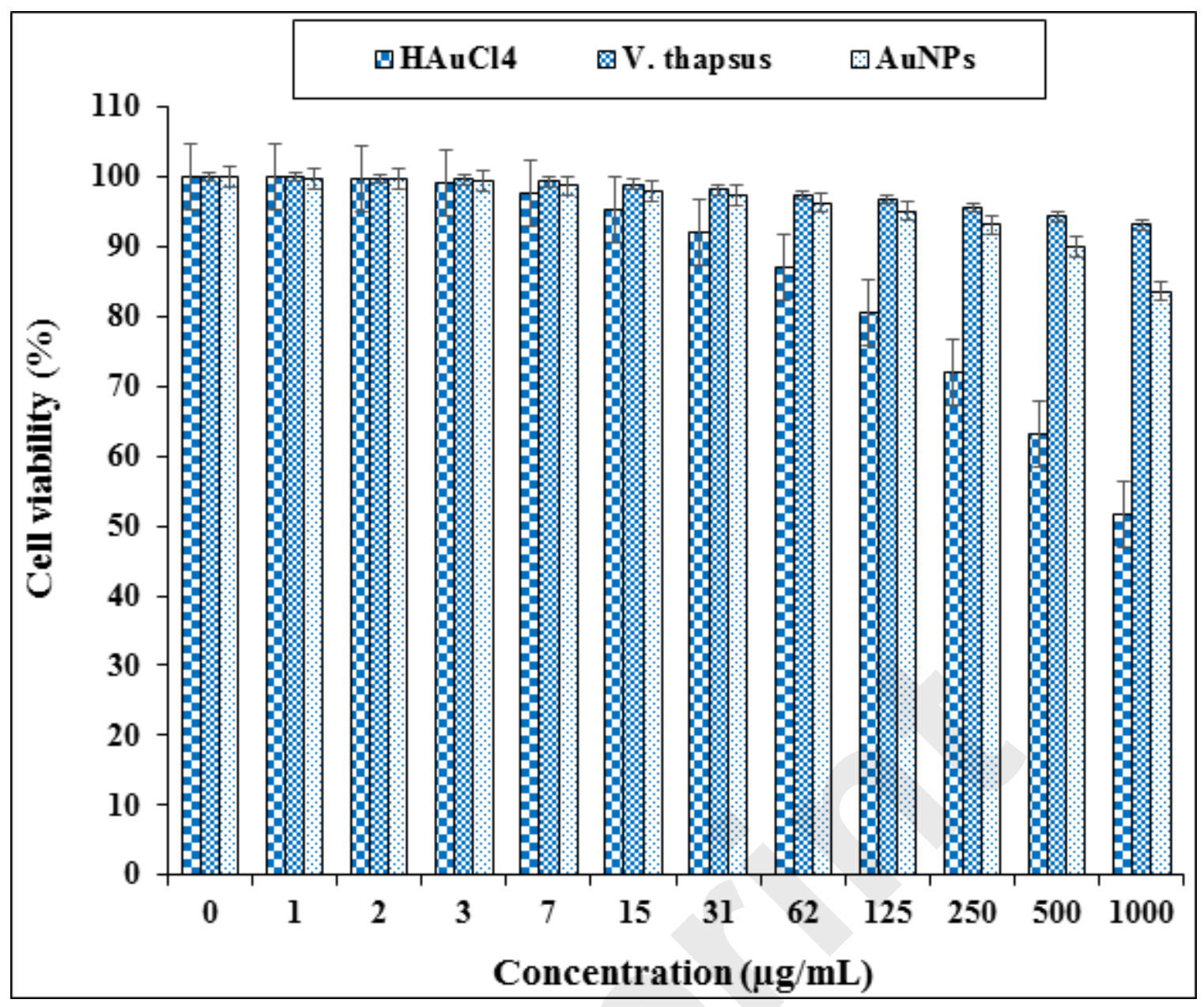

Figure 6. The cytotoxicity properties of $\mathrm{HAuCl}_{4}, V$. thapsus, and AuNPs against the HUVEC cell line. 


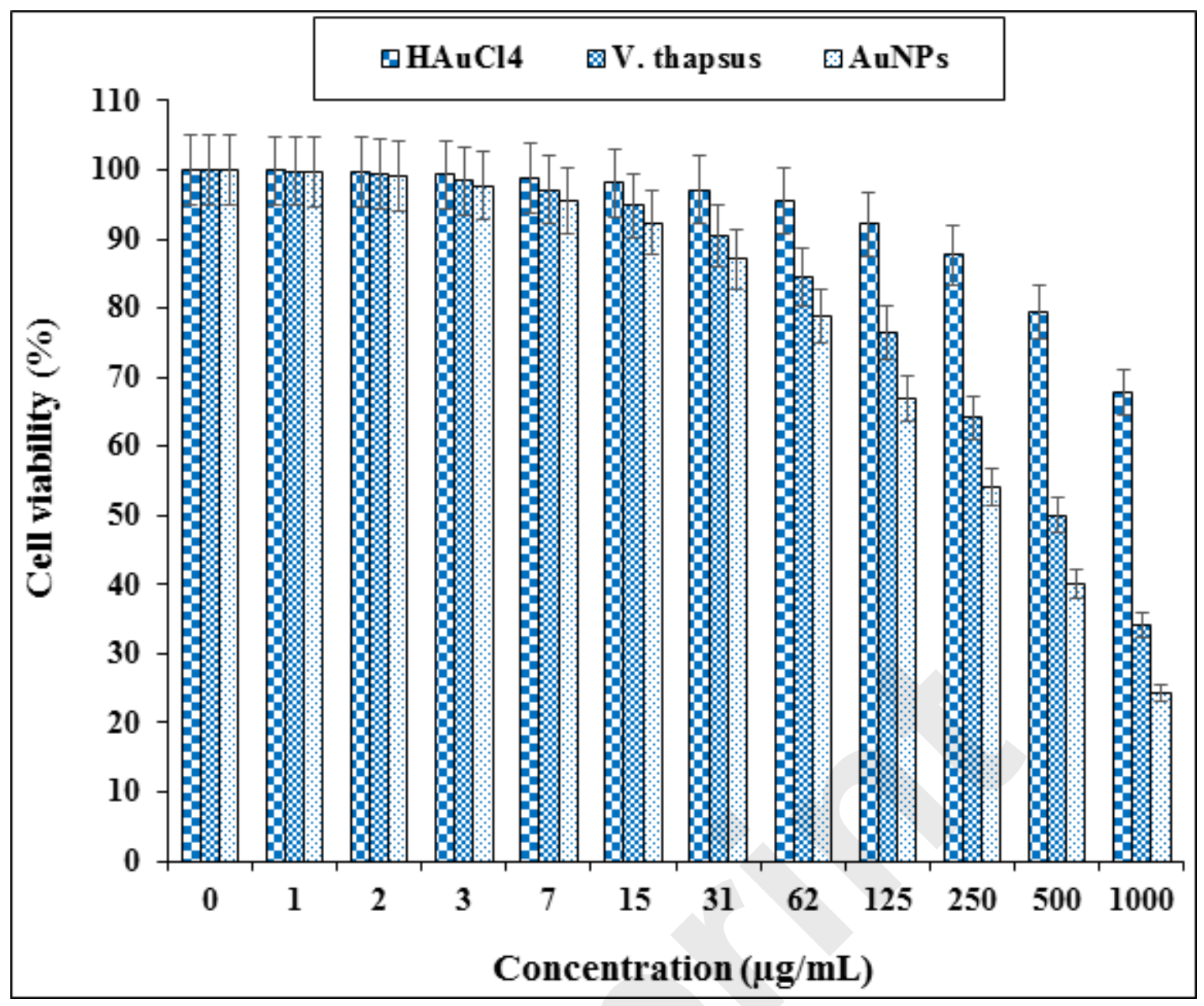

Figure 7. The anti-human lung cancer potentials of $\mathrm{HAuCl}_{4}, V$. thapsus, and AuNPs against well-differentiated bronchogenic adenocarcinoma (HLC-1) cell line. 


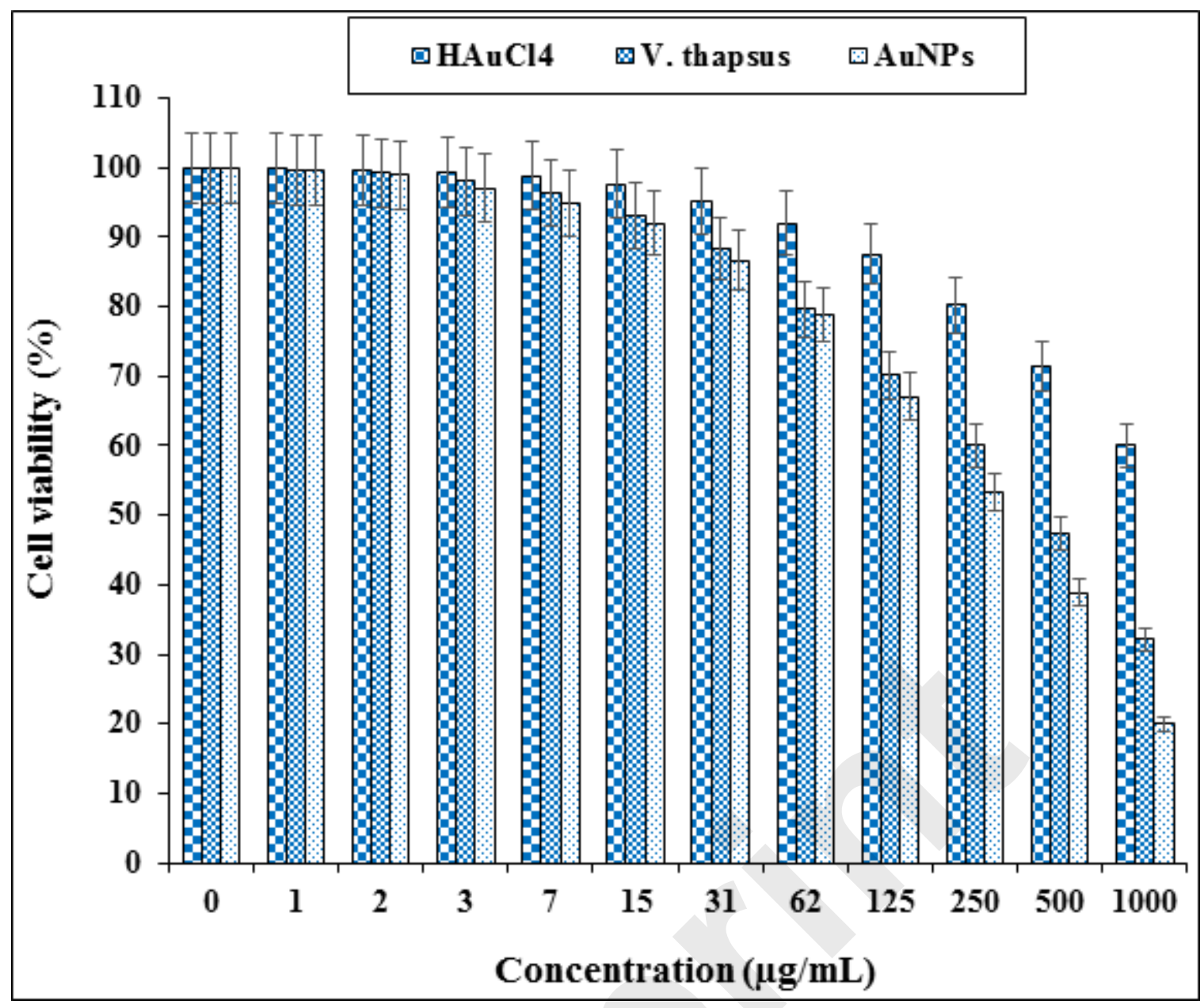

Figure 8. The anti-human lung cancer potentials of $\mathrm{HAuCl}_{4}, V$. thapsus, and AuNPs against moderately differentiated adenocarcinoma of the lung (LC-2/ad) cell line. 


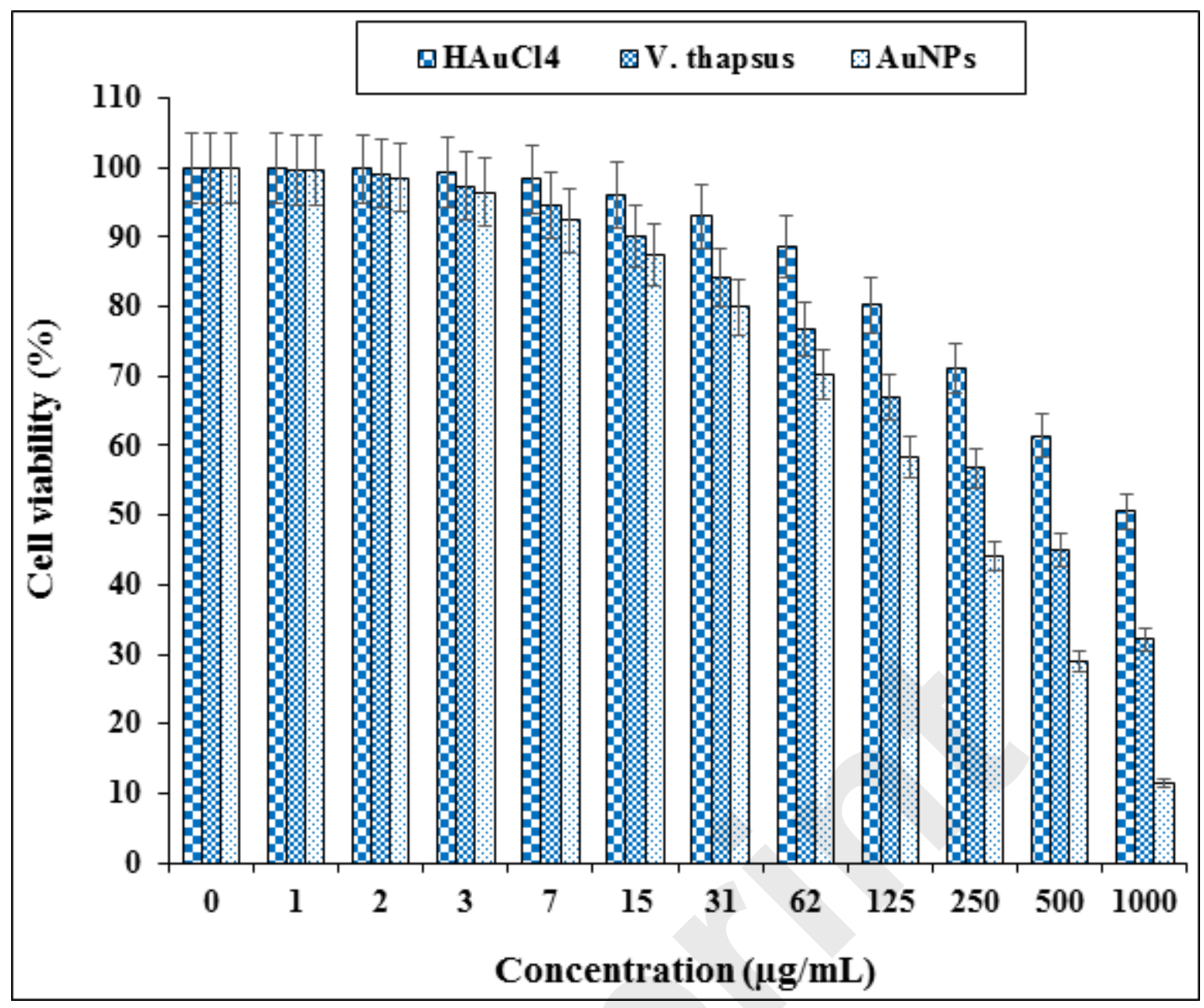

Figure 9. The anti-human lung cancer potentials of $\mathrm{HAuCl}_{4}, V$. thapsus, and AuNPs against poorly differentiated adenocarcinoma of the lung (PC-14) cell line. 